5 Transfers and discharges of PD patients should:

a be planned well in advance

b be negotiated with the patient

c reflect genuine clinical change

d include meetings of relevant staff

e involve members of the patient's wider social network, in selected cases

\begin{tabular}{|c|c|c|c|c|c|c|}
\hline \multicolumn{7}{|c|}{ MCQ answers } \\
\hline 1 & 2 & 3 & & 4 & & 5 \\
\hline a $T$ & a $F$ & & F & & $\mathrm{F}$ & \\
\hline b F & b F & & F & b & F & \\
\hline c $\mathrm{F}$ & c $T$ & & $\mathbf{T}$ & c & $\mathbf{T}$ & \\
\hline d $T$ & d $T$ & d & $\mathbf{T}$ & d & F & d \\
\hline e $F$ & e $F$ & e & $\mathbf{T}$ & e & F & $\mathrm{e}^{\prime}$ \\
\hline
\end{tabular}

\title{
Forthcoming Royal College of Psychiatrists CPD Events
}

19-21 September 1996, Hotel de France, Jersey Child and Adolescent Psychiatry Specialist Section Residential Conference. Contact: Annabel Thomas or Mairead Burke on extension 142 at the College

26-28 September 1996, Newcastle-upon-Tyne Section of the Psychiatry of Learning Disability Residential Conference. Contact: Annabel Thomas or Mairead Burke on extension 142 at the College

31 October 1996, Crown Hotel, Harrogate ECT Training Course. Contact: David Hills on extension 108 at the College

14-16 November 1996, Dublin

Social, Community and Rehabilitation Psychiatry Specialist Section Residential Conference. Contact: Annabel Thomas or Mairead Burke on extension 142 at the College
22 November 1996, Royal Society of Medicine, London

Depression and Prediction of Suicide. Joint meeting with Royal Society of Medicine. Contact: Annabel Thomas or Mairead Burke on extension 142 at the College

25 November 1996, Royal College of Psychiatrists Factitious Illness by Proxy - Munchausen Syndrome by Proxy. Contact: David Hills on extension 108 at the College

29 November 1996, Regent's College, London Behavioural-Cognitive Psychotherapy of Enduring Mental Disorder. Contact: Annabel Thomas or Mairead Burke on extension 142 at the College

\section{1-2 December 1996, London} Joint Meeting Liaison Group/ Society of Psychosomatic Research. Contact: David Hills on extension 108 at the College 